\title{
Control of neglected tropical diseases needs a long-term commitment
}

\author{
Yaobi Zhang ${ }^{1 *}$, Chad MacArthur ${ }^{2}$, Likezo Mubila ${ }^{3}$, Shawn Baker ${ }^{1}$
}

\begin{abstract}
Background: Neglected tropical diseases are widespread, particularly in sub-Saharan Africa, affecting over 2 billion individuals. Control of these diseases has gathered pace in recent years, with increased levels of funding from a number of governmental or non-governmental donors. Focus has currently been on five major 'tool-ready' neglected tropical diseases (lymphatic filariasis, onchocerciasis, schistosomiasis, soil-transmitted helminthiasis and trachoma), using a package of integrated drug delivery according to the World Health Organization guidelines for preventive chemotherapy.

Discussion: Success in controlling these neglected tropical diseases has been achieved in a number of countries in recent history. Experience from these successes suggests that long-term sustainable control of these diseases requires: (1) a long-term commitment from a wider range of donors and from governments of endemic countries; (2) close partnerships of donors, World Health Organization, pharmaceutical industries, governments of endemic countries, communities, and non-governmental developmental organisations; (3) concerted action from more donor countries to provide the necessary funds, and from the endemic countries to work together to prevent cross-border disease transmission; (4) comprehensive control measures for certain diseases; and (5) strengthened primary healthcare systems as platforms for the national control programmes and capacity building through implementation of the programmes.

Conclusions: The current level of funding for the control of neglected tropical diseases has never been seen before, but it is still not enough to scale up to the 2 billion people in all endemic countries. While more donors are sought, the stakeholders must work in a coordinated and harmonised way to identify the priority areas and the best delivery approaches to use the current funds to the maximum effect. Case management and other necessary control measures should be supported through the current major funding streams in order to achieve the objectives of the control of these diseases. For a long-term and sustainable effort, control of neglected tropical diseases should also be integrated into national primary healthcare systems.
\end{abstract}

\section{Background}

A group of chronic and debilitating conditions, caused by parasitic, bacterial, and viral infections, is defined as the neglected tropical diseases (NTDs) [1,2]. These NTDs are the most prevalent diseases in the poorest populations in the world, putting an estimated 2.7 billion people at risk [3]. They cause blindness (for example, onchocerciasis and trachoma) [4-7], disfigurement (for example, lymphatic filariasis, leishmaniasis, leprosy, and Buruli ulcer) [8-12], and are often life threatening at a later stage of the disease (for example, African trypanosomiasis,

\footnotetext{
* Correspondence: yzhang@hki.org

${ }^{1}$ Helen Keller International, Regional Office for Africa, Dakar, Senegal Full list of author information is available at the end of the article
}

Chagas disease, dengue fever, and schistosomiasis) [13-17]. They are also related to various clinical complications, such as anaemia and other forms of malnutrition (for example, hookworm infections, schistosomiasis, ascariasis, and trichuriasis) [18-23]. In terms of disabilityadjusted life years (DALYs), NTDs as a whole are among the top 10 leading causes of years of healthy life lost to long-term disability and premature death worldwide $[1,3]$. Sub-Saharan Africa bears the biggest burden of many of these NTDs, and the numbers of people afflicted by each of several of these diseases are simply striking [24], representing up to over $90 \%$ of the world's burden for some of these diseases. Moreover, these NTDs geographically overlap [1], and a significant proportion of
Ciomed Central

() 2010 Zhang et al; licensee BioMed Central Ltd. This is an Open Access article distributed under the terms of the Creative Commons Attribution License (http://creativecommons.org/licenses/by/2.0), which permits unrestricted use, distribution, and reproduction in any medium, provided the original work is properly cited. 
the poorest populations often harbours more than one of these NTDs [2,25,26]. These NTDs have severe socioeconomic consequences as they cause long-term illness, disfigurement, social stigma and marginalisation, and decreased productivity $[27,28]$. Therefore, successful control of NTDs will have a wide range of health and socioeconomic benefits to the poorest populations. The control of NTDs has now gained momentum in recent years with growing interest from the international community and funding from governmental or non-governmental donors, however more donors are needed to provide the funds to bridge the funding gap; the existing donors need to rethink their funding policy to include other necessary control measures for certain diseases in order to achieve the objectives, and the endemic countries need to commit themselves to the NTD control effort. This paper reviews experiences in the success of controlling these NTDs from recent history, and highlights the important aspects in the control of these NTDs in order to achieve a long-term sustainable effect.

\section{Discussion}

\section{Current situation in controlling the five major NTDs}

Control of the NTDs currently focuses on five major 'tool-ready' NTDs, lymphatic filariasis, onchocerciasis, schistosomiasis, soil-transmitted helminthiasis (hookworm infections, ascariasis, and trichuriasis) and trachoma in an integrated control programme [29]. This is because the drugs needed for these five NTDs are robust, safe, low cost and available by donation from pharmaceutical companies or by purchasing at relatively low costs. The current control strategy is mass drug administration (MDA) using the available drugs in a coordinated approach according to World Health Organization (WHO) guidelines on preventive chemotherapy [30]. This drug-based intervention delivers available drugs either alone or in combination to prevent morbidity caused by these NTDs, or in some cases to eliminate the diseases. To date, with the funds committed to deliver the available tools to the poorest people in need from external donors, a number of countries, for example, Bangladesh, Burkina Faso, Cameroon, Democratic Republic of Congo, Burundi, Ghana, Haiti, Mali, Nepal, Niger, Rwanda, Sierra Leone, Southern Sudan, Tanzania, Togo, and Uganda, have been able to implement integrated national NTD control programmes. Although the current strategy emphasises integrated control by preventive chemotherapy, control of each of these five major NTDs has its own endpoint targets and its own comprehensive measures to achieve these targets (Table 1).

\section{Onchocerciasis}

Onchocerciasis, or river blindness, is the second highest infectious cause of blindness in the world, and is now mainly distributed in 19 African countries, some foci in Yemen and parts of the Americas. There are 37 million people with onchocerciasis and 99\% of the cases are in Africa, with more than 102 million people at risk of the disease in Africa alone [31]. The control strategy is through mass administration of ivermectin (Mectizan) donated by Merck \& Co., Inc. through its Mectizan Donation Program http://www.mectizan.org.

In the Americas, the Onchocerciasis Elimination Program for the Americas (OEPA) was launched in 1992 to act as a technical and coordinating body for a multinational, multiagency coalition that facilitated the establishment of programmes for the semiannual mass administration of ivermectin in the six countries with onchocerciasis [32]. Significant progress has already been made in all six countries, with no new cases of onchocercal blindness being reported in the region, and it is anticipated that onchocerciasis could be eliminated from most of the remaining foci in the Americas by 2012 [32].

In Africa, the most successful control programme has been the Onchocerciais Control Program (OCP) which virtually eliminated river blindness from 11 countries first by vector control through spraying insecticides and subsequently through delivery of ivermectin [33]. In 1995 , onchocerciasis control was expanded to include areas outside the original OCP zone with a second programme, the African Program of Onchocerciasis Control (APOC). It adopted a strategy of community-directed treatment with ivermectin (CDTI) annually [34], delivering over 50 million treatments per year for onchocerciasis in 19 participating countries [31]. Through this strategy, the prevalence of onchocerciasis in these countries has been reduced from a precontrol level of $46.5 \%$ in 1995 to $28.5 \%$ in 2008 [31]. In some countries, for example, Senegal and Mali, longitudinal studies in three foci showed that after 15-17 years of annual or biannual CDTI, prevalence of onchocerciasis was reduced to $<1 \%$ [35]. This has ignited a hope of eliminating onchocerciasis from Africa.

\section{Lymphatic filariasis}

Lymphatic filariasis (LF), or elephantiasis, is widely distributed throughout the tropical and subtropical areas of Asia, Africa, the Western Pacific and some parts of the Americas [36,37]. Globally there are 120 million people infected with the parasite, causing tremendous morbidity, with 1.3 billion people at the risk of infection around the world $[3,36]$. Successful control of the disease is exemplified by elimination of LF in China $[38,39]$ and South Korea $[40,41]$. In China, the programme started in the $1950 \mathrm{~s}$, with a sustained government commitment to the elimination of lymphatic filariasis. Interventions included mass distribution of a 
Table 1 Risk factors, comprehensive control measures and endpoint control targets for each of five major neglected tropical diseases (NTDs)

\begin{tabular}{|c|c|c|c|}
\hline Disease & Major factors for human infection & $\begin{array}{l}\text { Comprehensive control } \\
\text { measures }\end{array}$ & Endpoint targets of control \\
\hline Onchocerciasis & $\begin{array}{l}\text { Parasites } \\
\text { Black flies (transmitting infective larvae during blood } \\
\text { feeding) } \\
\text { Human activities (near black fly breeding sites) }\end{array}$ & $\begin{array}{l}\text { Treatment with ivermectin } \\
\text { Health education for self- } \\
\text { protection } \\
\text { Case management }\end{array}$ & Elimination \\
\hline $\begin{array}{l}\text { Lymphatic } \\
\text { filariasis }\end{array}$ & $\begin{array}{l}\text { Parasites } \\
\text { Mosquitoes (transmitting infective larvae during blood } \\
\text { feeding) } \\
\text { Poor sanitation (mosquito breeding sites) } \\
\text { Human behaviour (without self-protection) }\end{array}$ & $\begin{array}{l}\text { Treatment with albendazole plus } \\
\text { ivermectin or diethylcarbamazine } \\
\text { Self-protection (bed net) } \\
\text { Health education for behavioural } \\
\text { change } \\
\text { Hygiene and sanitation } \\
\text { Case management }\end{array}$ & $\begin{array}{l}\text { Elimination as a public health } \\
\text { problem worldwide by the year } \\
2020\end{array}$ \\
\hline Schistosomiasis & $\begin{array}{l}\text { Parasites } \\
\text { Intermediate host snails in fresh water releasing infective } \\
\text { larvae } \\
\text { Poor hygiene and sanitation } \\
\text { Human behaviour (water contact and defecating/urinating } \\
\text { in/near water) }\end{array}$ & $\begin{array}{l}\text { Treatment with praziquantel } \\
\text { Snail management } \\
\text { Health education for behavioural } \\
\text { change } \\
\text { Hygiene and sanitation } \\
\text { Clean water supply } \\
\text { Hospitalisation of severe cases }\end{array}$ & Morbidity control \\
\hline $\begin{array}{l}\text { Soil-transmitted } \\
\text { helminthiasis }\end{array}$ & $\begin{array}{l}\text { Parasites } \\
\text { Poor hygiene and sanitation } \\
\text { Human behaviour (passing eggs to the environment in } \\
\text { faeces, barefoot, not washing hands, and so on) }\end{array}$ & $\begin{array}{l}\text { Treatment with albendazole or } \\
\text { mebendazole } \\
\text { Health education for behavioural } \\
\text { change } \\
\text { Hygiene and sanitation } \\
\text { Clean water supply }\end{array}$ & Morbidity control \\
\hline Trachoma & $\begin{array}{l}\text { Bacteria } \\
\text { Poor hygiene and sanitation } \\
\text { Human behaviour (lack of facial washing) }\end{array}$ & $\begin{array}{l}\text { SAFE strategy: } \\
\text { Surgical case management }(S) \\
\text { Treatment with azithromycin }(A) \\
\text { Clean water supply for facial } \\
\text { washing }(F) \\
\text { Hygiene and sanitation in the } \\
\text { environment (E) } \\
\text { Health education for behavioural } \\
\text { change }\end{array}$ & $\begin{array}{l}\text { Elimination as a blinding disease } \\
\text { worldwide by the year } 2020\end{array}$ \\
\hline
\end{tabular}

combination of diethylcarbamazine (DEC) tablets and DEC-fortified salt accompanied by intensive surveillance to monitor the prevalence of infection. Building on the successful experience and taking advantage of the available drug albendazole (donated by GlaxoSmithKline for areas coendemic with onchocerciasis), the Global Program to Eliminate Lymphatic Filariasis (GPELF) was established in 1997 to eliminate the disease as a public health problem worldwide by the year 2020. The strategy used is annual MDA with albendazole and DEC or albendazole and ivermectin to over $80 \%$ of the entire population at the risk of infection. Since 2000, GPELF has delivered MDA to around 700 million people worldwide, averting 32 million DALYs and an estimated 6.6 million newborns being prevented from the disease $[8,42]$. Data collected from the sentinel sites in several countries showed that the prevalence of microfilaraemia had been reduced by $60 \%$ to $100 \%$ after $5-6$ rounds of MDA [42], and that Egypt, after 5 rounds of MDA at high coverage, is likely to join the list of countries that has successfully eliminated LF [43]. Despite the progress made, 20 out of 71 endemic countries that require MDA are still yet to start the control programme.

\section{Schistosomiasis}

Schistosomiasis, or bilharzia, caused by the schistosome trematode, is one of the most debilitating helminthic diseases among rural populations. There are three major species that cause tremendous human morbidity, Schistosoma haematobium and Schistosoma mansoni predominantly in Africa, and Schistosoma japonicum in the Far East. Schistosomiasis can cause a wide range of symptoms and consequences depending on the species, the worm burden and the length of time infected [44]. Globally there are over 200 million people infected with the disease with many more at the risk of being infected, and the majority are in sub-Saharan Africa [45].

In China, the national control programme for schistosomiasis has restricted the disease to very limited areas with relatively low prevalence via decades of comprehensive control effort $[46,47]$. In Brazil and Egypt, similar successes in schistosomiasis control have also been 
achieved through MDA campaigns $[48,49]$. The current control strategy recommended by the WHO is to control morbidity due to schistosomiasis by MDA with praziquantel, targeting mainly school-age children and adults at high risk of infection. Preschool children and infants are also being considered for inclusion in the target population [50]. Unlike for other major NTDs there has been limited drug donation and so praziquantel has had to be purchased, although it is now available at low cost. In 2002, the Schistosomiasis Control Initiative was established with support from the Bill \& Melinda Gates Foundation, and has since delivered over 40 million treatments in sub-Saharan Africa using praziquantel [51]. The treatment made a significant impact on infection [52,53] and morbidity $[54,55]$ in the targeted populations. Currently there are 13 countries in sub-Saharan Africa that are implementing integrated NTD control programmes in which schistosomiasis control is an important component, however the majority of endemic countries are still yet to start such integrated control programmes.

\section{Soil-transmitted helminthiasis}

Soil-transmitted helminthiasis (STH) is caused by a group of parasitic nematode worms (most importantly, hookworms, Ascaris lumbricoides and Trichuris trichiura) through ingestion of parasite eggs or contact with skin-penetrating larvae that are present in the contaminated environment. These diseases are by far the most common NTDs in the developing world [3], affecting school-age children in particular and causing anaemia and other forms of malnutrition [18-22,56]. The control strategy is morbidity control through MDA using albendazole or mebendazole. Generally, control of STH is integrated into other programmes such as nutrition or school health as a deworming component, and is often part of schistosomiasis control programmes or as a collateral benefit from LF control programmes, as the same drug is used. Addition of mebendazole to vitamin A supplementation expanded the treatment to children of 12-59 months with a high coverage [57]. Children Without Worms (CWW) was established as a partnership between Johnson \& Johnson and the Task Force for Global Health to leverage the donation of mebendazole from Johnson \& Johnson to advocate for comprehensive and sustainable control of STH with a focus exclusively on school-age children http://www. childrenwithoutworms.org. Despite these efforts, less than $20 \%$ of the at-risk school-age population receive deworming treatment worldwide [58]; this is far short of the World Health Assembly's target to regularly treat 75\% of school-age children at risk of morbidity due to schistosomiasis and STH infections by 2010 [59]. As for schistosomiasis control, only a few countries are currently implementing or about to implement national integrated NTD control programmes that include STH control.

\section{Trachoma}

Trachoma, a recurrent eye infection caused by the bacteria, Chlamydia trachomatis, is the leading infectious (and thus preventable) cause of blindness worldwide. Repeated infection of the conjunctiva lining the underneath of the eyelid leads to scarring and the eventual turning-in of the eyelid, causing the eyelashes to rub against the eye itself. This painful condition, called trichiasis, eventually abraded the cornea and results in irreversible blindness.

Trachoma is endemic in 57 countries, particularly in sub-Saharan Africa, the Middle East and Asia, with the highest prevalence rates reported in sub-Saharan Africa [60]. The disease affects the poorest populations in the world. It is estimated that there are currently over 40 million people with the infectious form of the disease, and 8.2 million people that have trichiasis and are thus at risk of blindness. It is further estimated that over 7 million people have been blinded by trachoma [60].

The WHO, through the Global Alliance for the Elimination of Blinding Trachoma (GET2020), endorses the SAFE strategy (for 'Surgery for trichiasis, Antibiotics to treat infections, Facial cleaning and Environmental improvement to reduce transmission') [61,62] to eliminate this disease as a cause of blindness by the year 2020 [63]. In 1998, the International Trachoma Initiative (ITI), now part of the Task Force for Global Health, was established by the Edna McConnell Clark Foundation and Pfizer, Inc. [64], and has been working with governmental and non-governmental partners to support the implementation of the SAFE strategy in 18 endemic countries through the donation of the drug Zithromax (azithromycin) by Pfizer as the 'A' component of the SAFE strategy. As a result of this donation programme and the implementation of the other components of the SAFE strategy, in 2006 Morocco announced the elimination of trachoma as a public health problem. Several countries such as Ghana, Iran, Oman, Mexico and Saudi Arabia have since followed suit.

Trachoma control is currently included in the integrated control of NTDs but primarily for antibiotic distribution (the 'A' component). Funds to support the other components in the SAFE strategy, particularly surgery for trichiasis, have to be sourced elsewhere.

\section{Recommendations for a sustainable success in the control of NTDs \\ Long-term commitment}

The increasing commitment by the governmental and non-governmental donors in funding the control of NTDs has excited many. In 2006, the US Congress 
earmarked \$100 million for the United States Agency for International Development to target the aforementioned 'tool-ready' NTDs. In 2008, President Bush launched the NTD Initiative with $\$ 350$ million over 5 years to provide treatment to over 300 million people in developing countries. In 2009, President Obama announced a new global health initiative with $\$ 63$ billion over 6 years to address a range of global health problems including NTDs. The US Government has since steadily increased funding in NTD control over the last few years, from $\$ 15$ million per year during 2006-2008, to $\$ 25$ million in 2009 , and to $\$ 65$ million for 2010 . The UK government also announced a commitment of $£ 50$ million over 5 years towards NTD control and elimination. In 2009, a $\$ 34$ million grant was also provided by the Bill \& Melinda Gates Foundation to establish regional strategies and funding mechanisms and leverage new investments to control or eliminate NTDs by 2020 . Indeed, with the funding provided, many countries have now been able to implement their integrated NTD control programmes.

However, caution must be taken to avoid being overoptimistic and sending the wrong messages to donors for achieving the stated goals over a short period of time. Overoptimism can artificially raise donor expectations, which may not be met during the funding period. Experience shows that a successful control programme needs a long-term effort. It has been decades since schistosomiasis control programmes started in China in the $1950 \mathrm{~s}$ with a comprehensive control strategy [47] and in Brazil in the mid $1970 \mathrm{~s}$ with (mainly) chemotherapy [48], yet effort in control is still required and ongoing. There have been resurgences (or reemergences) of schistosomiasis in previously controlled areas $[47,65]$. With onchocerciasis, it took $15-17$ years of biannual MDA plus vector control to reduce the prevalence to a very low level as in Senegal and Mali [35]. It is therefore important that donors are aware that the overall objectives in controlling or eliminating NTDs may not be achieved after one or two rounds of a 5-year funding cycle using the current strategy, and that longterm commitment and investment are needed.

A long-term commitment is also required from the endemic countries. Current integrated control programmes are almost exclusively funded by external sources. It is recognised that the governments of endemic countries have to balance resource allocation for NTD control against a high burden of more dramatic diseases, and as such they rarely allocate budgets for implementation activities of NTD control programmes. However, in-kind contributions have been made as well as the commitment to integrate NTD activities into health systems. For long-term sustainable control, the endemic countries need to progressively take on the responsibility of such control programmes. This will also ensure that the residual levels of NTDs will be manageable within the health system when they cease to be of public health significance following intensive large-scale, relatively expensive, and community based interventions. It is also important for the beneficiary communities to realise that a long-term commitment is needed from them.

\section{Partnerships}

Successful control of NTDs needs a strong partnership involving all stakeholders across the various sectors. The successes of OCP, APOC, GPELF and GET2020 are all stories of partnerships of donors, the World Health Organization, pharmaceutical industries, governments of endemic countries, communities, and non-governmental developmental organisations (NGDOs). Commitment from the pharmaceutical industries to continue to donate the necessary drugs is also vital. Currently, Mectizan for onchocerciasis treatment will be donated by Merck for as long as is needed and with as much as is needed [66]. Albendazole for LF will be donated by GlaxoSmithKline for as long as necessary to eliminate LF to meet the current target of elimination by 2020 [67]. Pfizer donates Zithromax for trachoma treatment that is necessary to achieve the goal of the elimination of blinding trachoma by 2020. Johnson\&Johnson also donates mebendazole for STH treatment. However, the funds provided by donors to deliver these drugs to the populations in need are still not enough [68]. Therefore, in order to better use the limited resources, all the stakeholders within a country including donors and NGDOs, coordinated by governments of endemic countries, need to work together to identify those priority areas most in need and to plan and implement the control activities in a coordinated and harmonised way to avoid repetition and overlapping in both funding and effort. In this partnership, NGDOs have a very important role in assisting countries to raise funds and plan and implement the programmes, as has been demonstrated in onchocerciasis control [69].

\section{Concerted action}

Successful control of these diseases and the alleviation of the suffering of millions of people from long-term illness, disfigurement, social stigma and marginalisation, and decreased productivity require concerted action.

Concerted action is needed from donors. Currently, the US government, the UK government, the Bill\&Melinda Gates Foundation and some other private donors have provided some of the much-needed funds. Although G8 leaders put NTDs on the global health agenda and called for sustained action against NTDs, so far no major funding has come through from other major donor countries. With the improvement of the global economic situation, more donors need to fulfil 
their commitments to provide additional funds for the cause of NTD control so that efforts can be scaled up to reach all those people in need [70].

Concerted action is also needed from the endemic countries. Many of the NTDs spread across borders. Cross-border transmission of the NTDs is common because of the movement of populations. Expanding control efforts into bordering countries will be critical, as successful NTD control programmes in one country may be undermined by cross-border traffic from neighbouring countries where there are no NTD control programmes [68]. The neighbouring countries can also work together to exchange experience in planning, implementation, training and advocacy [51,71].

\section{Comprehensive control measures}

The current strategy for integrated control of NTDs is preventive chemotherapy using the available drugs [30] for one group of NTDs that share MDA as a common strategy. Therefore, the current major funding for the integrated NTD control programmes focuses almost exclusively on integrated MDA, ignoring a number of other components that are critical to the control, mitigation and in some cases the elimination of these diseases. For a long-term and sustainable impact, other measures (for example, clean water supply, hygiene and sanitation, behavioural changes, and vector management) must be addressed. The importance of socioeconomic development in NTD control needs to be recognised and appropriate collaboration sought when implementing NTD interventions. While these other measures will need concerted action from all relevant sectors and may not be fully addressed within an individual programme, for the purpose of morbidity control, extreme cases (for example, trichiasis, hydrocele, and elephantiasis) must be cared for and be included in the current funding. The control programme per se can actually benefit from such inclusion of case management as it has been shown that including lymphoedema management in the control programme can increase the community compliance with MDA [72]. In the case of trachoma control, the objective is global elimination of trachoma as a blinding disease by year 2020 using the SAFE strategy. In the current major funding, only the 'A' component is supported, that is, MDA with Zithromax, while the ' $S$ ', ' $F$ ' and 'E' components are overlooked. Without addressing the ' $\mathrm{F}$ ' and ' $\mathrm{E}$ ' components, the disease is guaranteed to return in the long term. There are currently 8.2 million people worldwide with trichiasis, the stage of trachoma that leads to irreversible blindness [60]. If funding for surgery for these cases (the ' $\mathrm{S}$ ' component) is not provided in the major funding, the main objective of GET2020 will never be achieved. There is a similar case for LF elimination for which disability management and prevention is of equal importance in the programme in order to attain the elimination goal. Another disease for which other complementary measures should be included is schistosomiasis. MDA with praziquantel alone showed excellent results in reducing prevalence and intensity of infection in the integrated control programmes [52,53,73], but it also showed difficulties in reducing infection in heavy endemic areas with close proximity to major water bodies [52], as the once a year treatment does not prevent reinfection. Even in areas where prevalence is reduced to very low levels by consecutive MDA, there is still a risk of recrudescence of the disease as shown in China $[47,65]$. The helminth control programme on Zanzibar Island is another good example of why comprehensive control measures are needed [74,75]. Therefore, for long-term sustainable control, there should be other measures including clean water supply, hygiene and sanitation such as latrine building and use, health education for behavioural change, and snail management if possible.

\section{Implementation through the primary healthcare system and capacity building}

In most developing countries, particularly in the poorest areas, there is a lack of fully functional infrastructure in the health service system. If strengthened, this system can be comprehensive, flexible in adjusting to changing disease patterns, permanent, and embedded in community life [76]. As an integrated NTD control programme is implemented in a country, it is important to avoid creating a separate parallel health service system relative to the existing one, and to avoid undermining the already under-resourced healthcare systems [77]. In areas with poor infrastructure and poor resources, a programme-oriented approach has been effective to achieve maximum effect in a short period of time in onchocerciasis control using community-directed interventions in APOC. However, for a long-term benefit and sustainable control programme on NTDs, it is vital to integrate NTD control into the existing primary healthcare system as routine health service operations where possible and thus to strengthen the infrastructure of the primary health system through such control programmes $[76,78,79]$. This is exemplified by the successful integration of NTD drug delivery through the national Child Health Days in Uganda [80,81]. Experience from the national integrated NTD control programme in Sierra Leone showed that implementing the programme involving the existing health service system actually helped rebuild and strengthen the system ( $M$ Hodges, personal communication).

The national NTD control programme belongs to the country and the beneficiary communities that need to take the ownership and responsibility over the implementation of the programme. For a successful control 
programme, one of the most important issues is the incountry capacity to implement such integrated control programmes. Under the current funding structure, an international organisation or an NGDO (or a consortium) is required to provide technical assistance and support in financial management to the national programme. It is vital that the government and the communities, rather than NGDOs, take the lead in planning and implementation of the programme. With the assistance from NGDOs, the programme can start from a limited scale to gain experience and build capacity through training and implementation, and then expand progressively.

\section{Conclusions}

Control of the NTDs has gained momentum in the last few years. The burden of these diseases on over 2 billion people in the poorest areas and the importance of controlling these NTDs for a wide range of benefits are recognised by the international community [70]. While impressive progress has been made in investment and control of the diseases, a long-term commitment from existing donors must be emphasised and funding from more governmental and non-governmental donors must be mobilised in order to ensure that the billions of people afflicted by the NTDs benefit from such a largescale international effort. With increased funding in the control of NTDs, the NTD control community must remain objective and maintain focus on maximum achievement with currently available resources. The current level of funding for NTD control has never been seen before, but it is still not enough to scale up to all people in all endemic countries, and the duration of assured funding is not known. The stakeholders must work in a coordinated and harmonised way to identify the priority areas and the best delivery approach to use the current funds to maximum effect. Case management and other necessary measures should be supported in the current funding stream in order to achieve the objectives of these disease controls. For a long-term and sustainable effort, control of NTDs should also be integrated into the primary healthcare system and strengthen the needed supporting structures where required.

\footnotetext{
Acknowledgements

Helen Keller International's programmes on the control of neglected tropical diseases in Africa received financial supports from the United States Agency for International Development through RTI International, the European Union, the Conrad N Hilton Foundation, the Lions Clubs International Foundation, the African Program for Onchocerciasis Control, the Mectizan Donation Program, the Nippon Foundation, the Government of Taiwan, the Government of South Korea through Heart to Heart Foundation, the World Food Program, and other private donors. Views expressed in this paper are solely those of the authors and not necessarily of the World Health Organization or the donor agencies.
}

\section{Author details}

${ }^{1}$ Helen Keller International, Regional Office for Africa, Dakar, Senegal. ${ }^{2}$ Helen Keller International, Headquarters, New York, the USA. ${ }^{3}$ World Health Organization, Regional Office for Africa, Harare, Zimbabwe.

\section{Authors' contributions}

YZ drafted the manuscript, and all authors contributed to and revised the manuscript.

\section{Competing interests}

The authors declare that they have no competing interests.

Received: 28 July 2010 Accepted: 29 October 2010

Published: 29 October 2010

\section{References}

1. Molyneux DH, Hotez PJ, Fenwick A: "Rapid-impact interventions": how a policy of integrated control for Africa's neglected tropical diseases could benefit the poor. PLoS Med 2005, 2:e336.

2. Hotez PJ, Molyneux DH, Fenwick A, Ottesen E, Ehrlich Sachs S, Sachs JD: Incorporating a rapid-impact package for neglected tropical diseases with programs for HIV/AIDS, tuberculosis, and malaria. PLoS Med 2006, 3: e102.

3. Hotez PJ, Molyneux DH, Fenwick A, Kumaresan J, Sachs SE, Sachs JD, Savioli L: Control of neglected tropical diseases. N Engl J Med 2007, 357:1018-1027.

4. Mathew AA, Turner A, Taylor HR: Strategies to control trachoma. Drugs 2009, 69:953-970.

5. Wright HR, Turner A, Taylor HR: Trachoma. Lancet 2008, 371:1945-1954.

6. Stingl P: Onchocerciasis: developments in diagnosis, treatment and control. Int J Dermatol 2009, 48:393-396.

7. Berger IB, Nnadozie J: Onchocerciasis and other eye problems in developing countries: a challenge for optometrists. J Am Optom Assoc 1993, 64:699-702.

8. Ottesen EA, Hooper PJ, Bradley M, Biswas G: The global programme to eliminate lymphatic filariasis: health impact after 8 years. PLOS Negl Trop Dis 2008, 2:e317.

9. Hepburn NC: Cutaneous leishmaniasis: an overview. J Postgrad Med 2003, 49:50-54.

10. Barrett R: Self-mortification and the stigma of leprosy in northern India. Med Anthropol Q 2005, 19:216-230.

11. Hartzell JD, Zapor M, Peng S, Straight T: Leprosy: a case series and review. South Med J 2004, 97:1252-1256.

12. Pszolla N, Sarkar MR, Strecker W, Kern P, Kinzl L, Meyers WM, Portaels F: Buruli ulcer: a systemic disease. Clin Infect Dis 2003, 37:e78-82.

13. Fevre EM, Wissmann BV, Welburn SC, Lutumba P: The burden of human african trypanosomiasis. PLoS Negl Trop Dis 2008, 2:e333.

14. Kennedy PG: The continuing problem of human African trypanosomiasis (sleeping sickness). Ann Neurol 2008, 64:116-126.

15. Sanchez-Sancho F, Campillo NE, Paez JA: Chagas disease: progress and new perspectives. Curr Med Chem 2010, 17:423-52.

16. Ong A, Sandar M, Chen MI, Sin LY: Fatal dengue hemorrhagic fever in adults during a dengue epidemic in Singapore. Int J Infect Dis 2007, 11:263-267.

17. Kheir MM, Eltoum IA, Saad AM, Ali MM, Baraka OZ, Homeida MM: Mortality due to Schistosomiasis mansoni: a field study in Sudan. Am J Trop Med Hyg 1999, 60:307-310.

18. Hotez PJ, Molyneux DH: Tropical anemia: one of Africa's great killers and a rationale for linking malaria and neglected tropical disease control to achieve a common goal. PLoS Negl Trop Dis 2008, 2:e270.

19. Brooker S, Hotez PJ, Bundy DA: Hookworm-related anaemia among pregnant women: a systematic review. PLoS Negl Trop Dis 2008, 2:e291.

20. Stephenson LS: Helminth parasites, a major factor in malnutrition. World Health Forum 1994, 15:169-172.

21. Stephenson LS, Latham MC, Ottesen EA: Malnutrition and parasitic helminth infections. Parasitology 2000, 121(Suppl):S23-38.

22. Bates I, McKew S, Sarkinfada F: Anaemia: a useful indicator of neglected disease burden and control. PLoS Med 2007, 4:e231.

23. Friedman JF, Kanzaria HK, McGarvey ST: Human schistosomiasis and anemia: the relationship and potential mechanisms. Trends Parasitol 2005, 21:386-392. 
24. Hotez PJ, Kamath A: Neglected tropical diseases in sub-saharan Africa: review of their prevalence, distribution, and disease burden. PLoS Negl Trop Dis 2009, 3:e412.

25. Raso G, Luginbuhl A, Adjoua CA, Tian-Bi NT, Silue KD, Matthys B, Vounatsou P, Wang Y, Dumas ME, Holmes E, Singer BH, Tanner M, N'goran EK, Utzinger J: Multiple parasite infections and their relationship to self-reported morbidity in a community of rural Cote d'Ivoire. Int J Epidemiol 2004, 33:1092-1102.

26. McKenzie FE: Polyparasitism. Int J Epidemiol 2005, 34:221-222, author reply 222-223.

27. Conteh L, Engels T, Molyneux DH: Socioeconomic aspects of neglected tropical diseases. Lancet 2010, 375:239-247.

28. Ehrenberg JP, Ault SK: Neglected diseases of neglected populations: thinking to reshape the determinants of health in Latin America and the Caribbean. BMC Public Health 2005, 5:119.

29. Brady MA, Hooper PJ, Ottesen EA: Projected benefits from integrating NTD programs in sub-Saharan Africa. Trends Parasitol 2006, 22:285-291.

30. World Health Organization: Preventive Chemotherapy in Human Helminthiasis Geneva, Switzerland: World Health Organization; 2006.

31. African Programme for Onchocerciasis Control: Report of the sixth meeting of national task forces, October 2009. Wkly Epidemiol Rec 2010, 85:23-28.

32. Sauerbrey M: The Onchocerciasis Elimination Program for the Americas (OEPA). Ann Trop Med Parasitol 2008, 102(Suppl 1):25-29.

33. Hougard JM, Poudiougo P, Zerbo G, Meyer R, Guillet P, Agoua H, Seketeli A, Akpoboua A, Sowah S, Samba EM, et al: Control of onchocerciasis vectors in West Africa: description of the logistics adapted for a large-scale public health program [in French]. Sante 1994, 4:389-398.

34. Amazigo U: The African Programme for Onchocerciasis Control (APOC). Ann Trop Med Parasitol 2008, 102(Suppl 1):19-22.

35. Diawara L, Traore MO, Badji A, Bissan Y, Doumbia K, Goita SF, Konate L, Mounkoro K, Sarr MD, Seck AF, Toé L, Tourée S, Remme JH: Feasibility of onchocerciasis elimination with ivermectin treatment in endemic foci in Africa: first evidence from studies in Mali and Senegal. PLoS Negl Trop Dis 2009, 3:e497.

36. Ottesen EA, Duke BO, Karam M, Behbehani K: Strategies and tools for the control/elimination of lymphatic filariasis. Bull World Health Organ 1997, 75:491-503.

37. Ottesen EA: Lymphatic filariasis: treatment, control and elimination. Adv Parasitol 2006, 61:395-441.

38. Sun DJ: Global significance of the elimination of lymphatic filariasis in China [in Chinese]. Zhongguo Ji Sheng Chong Xue Yu Ji Sheng Chong Bing Za Zhi 2005, 23(5 Suppl):329-331.

39. World Health Organization: Global programme to eliminate lymphatic filariasis. Wkly Epidemiol Rec 2008, 83:333-341.

40. Cheun HI, Lee JS, Cho SH, Kong Y, Kim TS: Elimination of lymphatic filariasis in the Republic of Korea: an epidemiological survey of formerly endemic areas, 2002-2006. Trop Med Int Health 2009, 14:445-449.

41. Cheun HI, Kong Y, Cho SH, Lee JS, Chai JY, Lee JK, Kim TS: Successful control of lymphatic filariasis in the Republic of Korea. Korean J Parasitol 2009, 47:323-335.

42. World Health Organization: Global programme to eliminate lymphatic filariasis. Wkly Epidemiol Rec 2009, 84:437-444.

43. Ramzy RM, El Setouhy M, Helmy H, Ahmed ES, Abd Elaziz KM, Farid HA, Shannon WD, Weil GJ: Effect of yearly mass drug administration with diethylcarbamazine and albendazole on bancroftian filariasis in Egypt: a comprehensive assessment. Lancet 2006, 367:992-999.

44. Fenwick A, Zhang Y: Schistosomiasis. In Infectious Diseases.. 3 edition. Edited by: Cohen J, Opal SM, Powderly WG. Amsterdam, The Netherlands: Elsevier; 2010

45. Steinmann P, Keiser J, Bos R, Tanner M, Utzinger J: Schistosomiasis and water resources development: systematic review, meta-analysis, and estimates of people at risk. Lancet Infect Dis 2006, 6:411-425.

46. Xianyi C, Liying W, Jiming C, Xiaonong Z, Jiang Z, Jiagang G, Xiaohua W, Engels D, Minggang C: Schistosomiasis control in China: the impact of a 10-year World Bank Loan Project (1992-2001). Bull World Health Organ 2005, 83:43-48.

47. Wang L, Utzinger J, Zhou XN: Schistosomiasis control: experiences and lessons from China. Lancet 2008, 372:1793-1795

48. Katz N: Schistosomiasis control in Brazil. Mem Inst Oswaldo Cruz 1998, 93(Suppl 1):33-35.
49. Webbe G, el Hak S: Progress in the control of schistosomiasis in Egypt 1985-1988. Trans R Soc Trop Med Hyg 1990, 84:394-400.

50. Stothard JR, Gabrielli AF: Schistosomiasis in African infants and preschool children: to treat or not to treat? Trends Parasitol 2007, 23:83-86.

51. Fenwick A, Webster JP, Bosque-Oliva E, Blair L, Fleming FM, Zhang Y, Garba A, Stothard JR, Gabrielli AF, Clements AC, Kabatereine NB, Toure S, Dembele R, Nyandindi U, Mwansa J, Koukounari A: The Schistosomiasis Control Initiative $(\mathrm{SCl})$ : rationale, development and implementation from 2002-2008. Parasitology 2009, 136:1719-1730.

52. Zhang Y, Koukounari A, Kabatereine N, Fleming F, Kazibwe F, Tukahebwa E, Stothard JR, Webster JP, Fenwick A: Parasitological impact of 2-year preventive chemotherapy on schistosomiasis and soil-transmitted helminthiasis in Uganda. BMC Med 2007, 5:27.

53. Toure S, Zhang Y, Bosque-Oliva E, Ky C, Ouedraogo A, Koukounari A, Gabrielli AF, Bertrand S, Webster JP, Fenwick A: Two-year impact of single praziquantel treatment on infection in the national control programme on schistosomiasis in Burkina Faso. Bull World Health Organ 2008, 86:780-787, A.

54. Kabatereine NB, Brooker S, Koukounari A, Kazibwe F, Tukahebwa EM, Fleming FM, Zhang Y, Webster JP, Stothard JR, Fenwick A: Impact of a national helminth control programme on infection and morbidity in Ugandan schoolchildren. Bull World Health Organ 2007, 85:91-99.

55. Koukounari A, Gabrielli AF, Toure S, Bosque-Oliva E, Zhang Y, Sellin B, Donnelly CA, Fenwick A, Webster JP: Schistosoma haematobium infection and morbidity before and after large-scale administration of praziquantel in Burkina Faso. J Infect Dis 2007, 196:659-669.

56. King CH, Dickman K, Tisch DJ: Reassessment of the cost of chronic helmintic infection: a meta-analysis of disability-related outcomes in endemic schistosomiasis. Lancet 2005, 365:1561-1569.

57. World Health Organization: How to Add Deworming to Vitamin A Distribution Geneva, Switzerland: World Health Organization; 2004.

58. CWW: A closer look at soil-transmitted helminth (STH) infections. [http:// www.childrenwithoutworms.org/].

59. WHO: Deworming for health and development. [http://whqlibdoc.who.int/ hq/2005/who_cds_cpe_pvc_2005.14.pdf].

60. Burton MJ, Mabey DC: The global burden of trachoma: a review. PLoS Negl Trop Dis 2009, 3:e460.

61. West SK: Blinding trachoma: prevention with the safe strategy. Am J Trop Med Hyg 2003, 69(5 Suppl):18-23.

62. Chami Y, Hammou J, Mahjour J: Lessons from the moroccan national trachoma control programme. Community Eye Health 2004, 17:59.

63. Mariotti SP, Pararajasegaram R, Resnikoff S: Trachoma: looking forward to Global Elimination of Trachoma by 2020 (GET 2020). Am J Trop Med Hyg 2003, 69(5 Suppl):33-35.

64. Kumaresan JA, Mecaskey JW: The global elimination of blinding trachoma: progress and promise. Am J Trop Med Hyg 2003, 69(5 Suppl):24-28.

65. Liang S, Yang C, Zhong B, Qiu D: Re-emerging schistosomiasis in hilly and mountainous areas of Sichuan, China. Bull World Health Organ 2006, 84:139-144.

66. Merck: Merck MECTIZAN Donation Program. [http://www.merck.com/ corporate-responsibility/access/access-developing-emerging/mectizandonation-riverblindness/approach.html].

67. GlaxoSmithKline: Our commitment on LF. [http://www.gsk.com/filariasis/ commitment.htm].

68. Fenwick $A$, Zhang $Y$, Stoever $\mathrm{K}$ : Control of the neglected tropical diseases in sub-Saharan Africa: the unmet needs. International Health 2009, 1:61-70.

69. Haddad D: The NGDO co-ordination group for onchocerciasis control. Ann Trop Med Parasitol 2008, 102(Suppl 1):35-38.

70. Molyneux $\mathrm{DH}$ : Neglected tropical diseases - beyond the tipping point? Lancet 2010, 375:3-4.

71. Garba A, Toure S, Dembele R, Bosque-Oliva E, Fenwick A: Implementation of national schistosomiasis control programmes in West Africa. Trends Parasitol 2006, 22:322-326.

72. Cantey PT, Rout J, Rao G, Williamson J, Fox LM: Increasing compliance with mass drug administration programs for lymphatic filariasis in India through education and lymphedema management programs. PLOS Negl Trop Dis 2010, 4:e728.

73. Tohon ZB, Mainassara HB, Garba A, Mahamane AE, Bosque-Oliva E, Ibrahim ML, Duchemin JB, Chanteau S, Boisier P: Controlling schistosomiasis: significant decrease of anaemia prevalence one year 
after a single dose of praziquantel in Nigerian schoolchildren. PLoS Negl Trop Dis 2008, 2:e241.

74. Knopp S, Mohammed KA, Rollinson D, Stothard JR, Khamis IS, Utzinger J, Marti $\mathrm{H}$ : Changing patterns of soil-transmitted helminthiases in Zanzibar in the context of national helminth control programs. Am J Trop Med Hyg 2009, 81:1071-1078.

75. Stothard JR, French MD, Khamis IS, Basanez MG, Rollinson D: The epidemiology and control of urinary schistosomiasis and soil-transmitted helminthiasis in schoolchildren on Unguja Island, Zanzibar. Trans $R$ Soc Trop Med Hyg 2009, 103:1031-1044.

76. Gyapong JO, Gyapong M, Yellu N, Anakwah K, Amofah G, Bockarie M, Adjei S: Integration of control of neglected tropical diseases into healthcare systems: challenges and opportunities. Lancet 2010, 375:160-165.

77. McCoy D, Chopra M, Loewenson R, Aitken JM, Ngulube T, Muula A, Ray S, Kureyi T, ljumba $P$, Rowson M: Expanding access to antiretroviral therapy in sub-saharan Africa: avoiding the pitfalls and dangers, capitalizing on the opportunities. Am J Public Health 2005, 95:18-22.

78. Victora CG, Hanson K, Bryce J, Vaughan JP: Achieving universal coverage with health interventions. Lancet 2004, 364:1541-1548.

79. Hopkins AD: Challenges for the integration of mass drug administrations against multiple 'neglected tropical diseases'. Ann Trop Med Parasitol 2009, 103(Suppl 1):S23-31.

80. Kabatereine NB, Fleming FM, Nyandindi U, Mwanza JC, Blair L: The control of schistosomiasis and soil-transmitted helminths in East Africa. Trends Parasitol 2006, 22:332-339.

81. Kolaczinski JH, Kabatereine NB, Onapa AW, Ndyomugyenyi R, Kakembo AS, Brooker S: Neglected tropical diseases in Uganda: the prospect and challenge of integrated control. Trends Parasitol 2007, 23:485-493.

\section{Pre-publication history}

The pre-publication history for this paper can be accessed here: http://www.biomedcentral.com/1741-7015/8/67/prepub

\section{Submit your next manuscript to BioMed Central and take full advantage of:}

- Convenient online submission

- Thorough peer review

- No space constraints or color figure charges

- Immediate publication on acceptance

- Inclusion in PubMed, CAS, Scopus and Google Scholar

- Research which is freely available for redistribution 